УДК 676.166:541.12

\title{
СВОЙСТВА ПЕРОКСИДНОЙ ЦЕЛЛЮЛОЗЫ ИЗ ОДНОЛЕТНИХ РАСТЕНИЙ. 7. ОТБЕЛКА ЦЕЛЛЮЛОЗЫ ИЗ ПШЕНИЧНОЙ СОЛОМЫ*
}

\author{
() Р.3. Пен**, Н.В. Каретникова, И.А. Вшивкова, И.Л. Шапиро \\ Сибирский государственный технологический университет, пр. Мира, 82, \\ Красноярск, 660049 (Россия), e-mail: sibstu@sibstu.ru, robertpen@yandex.ru
}

\begin{abstract}
Пероксидная целлюлоза (выход 55,7\%, белизна 76,9\%) получена делигнификацией реакционной смесью « $\mathrm{H}_{2} \mathrm{O}_{2}-$

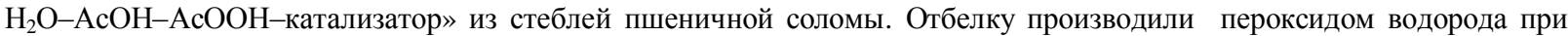
pH 10,5 и концентрации волокнистой суспензии $10 \%$ в одну ступень по технологии, обычной для этого процесса. Зависимость белизны и химических потерь целлюлозы от концентрации $\mathrm{H}_{2} \mathrm{O}_{2}$ (диапазон $0,5-1,5 \%$ ), температуры $\left(40-50{ }^{\circ} \mathrm{C}\right)$ и продолжительности отбелки (30-90 мин) аппроксимировали уравнениями регрессии второго порядка. Установлена легкая белимость пероксидной соломенной целлюлозы. Оптимальные условия отбелки найдены методом нелинейного программирования: температура $-40{ }^{\circ} \mathrm{C}$; концентрация $\mathrm{H}_{2} \mathrm{O}_{2}-1,0 \%$; продолжительность - 63 мин. Результаты отбелки по оптимальному режиму: белизна целлюлозы - 89\% (соответствует ГОСТ для лиственной сульфатной целлюлозы), химические потери $-5,7 \%$.
\end{abstract}

Ключевые слова: пероксидная целлюлоза, целлюлоза из соломы, пероксидная варка, отбелка целлюлозы.

\section{Введение}

Основное количество соломенной целлюлозы потребляется в беленом виде в композиции с древесной целлюлозой для производства писчей и печатной бумаги средних и высших сортов. Отбеливается соломенная целлюлоза значительно легче, чем хвойная сульфатная. Высокая степень белизны может быть достигнута двухступенчатой гипохлоритной отбелкой, но при этом отмечается значительное снижение вязкости и ухудшение прочностных свойств [2]. Лучшие результаты получаются при использовании в качестве отбеливающих реагентов диоксида хлора и пероксида водорода.

\section{Экспериментальная часть}

Высушенную на воздухе солому пшеницы Triticum sp., заготовленную по окончании вегетационного периода (2010-2011 г., Емельяновсий район, Красноярский край), измельчали в лабораторной дисковой мельнице и фракционировали с помощью набора сит. Для экспериментов использовали фракцию, оставшуюся на ситах с круглыми отверстиями диаметром 5 и 7 мм.

\footnotetext{
Пен Роберт Зусьевич - профессор кафедры целлюлознобумажного производства и химических волокон, доктор технических наук, профессор, e-mail: robertpen@yandex.ru Каретникова Наталья Викторовна - доцент кафедры целлюлозно-бумажного производства и химических волокон, кандидат химических наук

Виивкова Ирина Анатольевна - аспирант кафедры целлюлозно-бумажного производства и химических волокон

Шапиро Ида Львовна - доцент кафедры целлюлознобумажного производства и химических волокон, кандидат технических наук
}

Варку проводили по изотермическому режиму со свежеприготовленной смесью ледяной уксусной кислоты и пергидроля (30\%) в соотношении, соответственно, 65 : 35 (по объему) с добавлением каталитических количеств вольфрамата натрия. Условия варки: жидкостный модуль 6; концентрация вольфрамата натрия в варочном растворе 0,0015 гмоль/дм ${ }^{3}$; температура варки $98^{\circ} \mathrm{C}$; продолжительность -3 ч. Результаты варки: выход целлюлозы из сырья 55,7\%; непровар отсутствовал; массовая доля лигнина в целлюлозе $-4,37 \%$; белизна $-76,9 \%$.

\footnotetext{
*Предыдущее сообщение см. [1]

** Автор, с которым следует вести переписку.
} 
Предварительные эксперименты показали, что полученная пероксидная (перуксусная) целлюлоза может быть эффективно отбелена пероксидом водорода в щелочной среде в одну ступень при значительно более «мягких» условиях, чем сульфитная и сульфатная древесная целлюлоза, поэтому серию следующих экспериментов выполнили при относительно низких температурах. Целлюлозу обрабатывали раствором пероксида водорода при рН 10,5. Для стабилизации величины рН к реакционной смеси прибавляли гидроксид и силикат натрия. Начальные концентрации волокнистой суспензии $10 \%$, гидроксида натрия $0,50 \%$ и силиката натрия 4,0\% в серии опытов не меняли.

В качестве переменных условий отбелки выбрали наиболее важные факторы на основании априорной информации и результатов предварительных опытов: температуру отбелки $X_{1}$ (интервал варьирования $\left.40-50{ }^{\circ} \mathrm{C}\right)$, начальную концентрацию пероксида водорода $X_{2}(0,5-1,5 \%)$ и продолжительность процесса $X_{3}$ (30...90 мин). Переменные факторы варьировали в соответствии с планом эксперимента Бокса второго порядка (14 режимов). Для оценки дисперсии воспроизводимости добавили два опыта в центральной точке плана. Значения переменных факторов приведены в таблице 1 (столбцы 1, 2, 3).

Результаты отбелки характеризовали двумя выходными параметрами: белизной по ГОСТ 30113 $\left(Y_{1}, \%\right)$ и химическими потерями $\left(Y_{2}, \%\right)$ целлюлозы (табл. 1 , столбцы 4,5$)$.

Зависимости выходных параметров $Y_{1}$ и $Y_{2}$ от переменных факторов отбелки аппроксимировали уравнениями регрессии второго порядка. Математическую обработку выполнили средствами блока Design of Experiments (DOE) в пакете прикладных программ Statgraphics Centurion XVI [3].

Таблица 1. Условия и результаты опытов

\begin{tabular}{c|c|c|c|c}
\hline \multicolumn{2}{|c|}{ Условия опытов } & & \multicolumn{2}{|c}{ Результаты опытов } \\
\hline$X_{1},{ }^{\circ} \mathrm{C}$ & $X_{2}, \%$ & $X_{3}$, мин & $Y_{1}, \%$ & 7,0 \\
\hline 50 & 1,5 & 90 & 93,4 & 7,1 \\
50 & 1,5 & 30 & 92,5 & 7,4 \\
50 & 0,5 & 90 & 90,5 & 6,8 \\
50 & 0,5 & 30 & 89,6 & 7,3 \\
50 & 1,0 & 60 & 89,9 & 6,4 \\
45 & 1,5 & 60 & 91,0 & 6,1 \\
45 & 0,5 & 60 & 88,4 & 6,9 \\
45 & 1,0 & 90 & 91,5 & 6,3 \\
45 & 1,0 & 30 & 88,2 & 6,2 \\
45 & 1,0 & 60 & 90,3 & 6,4 \\
45 & 1,0 & 60 & 90,1 & 6,4 \\
40 & 1,5 & 90 & 92,6 & 6,4 \\
40 & 1,5 & 30 & 89,5 & 6,2 \\
40 & 0,5 & 90 & 87,0 & 8,1 \\
4
\end{tabular}

\section{Обсуждение результатов}

На рисунке 1 представлена стандартизованная карта Парето, отражающая вклад каждого из эффектов (элементов уравнений регрессии) в результат процесса. Длина горизонтальных полос на графиках пропорциональна $t$-статистике для каждого эффекта. Вертикальные линии, пересекающие полосы в левой части графиков, соответствуют границам статистической значимости эффектов при доверительной вероятности 0,9 .

На основании полученных оценок для дальнейшего анализа зависимости белизны целлюлозы $Y_{1}$ от условий отбелки выбраны четыре статистически значимых эффекта: все три главных (линейных) эффекта и взаимодействие $X_{1} X_{2}$. Уравнение регрессии принимает вид

$$
\hat{Y}_{1}=66,59+0,40 X_{1}+11,46 X_{2}+0,0313 X_{3}-0,176 X_{1} X_{2}
$$

Сравнение вычисленных по уравнению (1) прогнозируемых значений выходного параметра $\hat{Y}_{1}$ с экспериментально полученными значениями белизны $Y_{1}$ показало хорошее соответствие между этими величинами. Результаты дисперсионного анализа (ANOVA), приведенные в таблице 2, подтверждают адекватность уравнения (1) реальному процессу (результатам наблюдений), так как значение уровня значимости 
$P=0,1309$ для дисперсионного $F$-отношения в строке Lack-of-fit значительно превышает критическую величину 0,05 . На хорошие прогностические свойства уравнения указывает также высокое значение коэффициента детерминации $R^{2}$.

Величина критерия Дарбина-Уотсона (DW) указывает на выполнение одного из условий регрессионного анализа - отсутствие корреляций остатков $(Y-\hat{Y})$, поскольку $P_{\mathrm{DW}}=0,234>0,05$ (табл. 2).

На рисунке 2 изображены поверхности отклика, наглядно иллюстрирующие зависимость белизны целлюлозы от переменных факторов процесса отбелки.

Увеличение каждого из включенных в исследование переменных факторов сопровождается повышением белизны целлюлозы, это не противоречит априорной информации о закономерностях процесса отбелки [2]. Зависимости, отображенные на рисунках 2-А и 2-Б, представляют собой наклонные плоскости, поскольку эффекты взаимодействий продолжительности отбелки с остальными факторами и все нелинейные (квадратичные) эффекты отсутствуют в уравнении регрессии (статистически незначимы). Небольшой по абсолютной величине эффект взаимодействия первого порядка между температурой и начальной концентрацией пероксида водорода проявляется в том, что при низком значении любого из этих факторов влияние другого на белизну менее энергично, чем при их высоком значении (рис. 2-В).

Для моделирования зависимости химических потерь целлюлозы от условий отбелки, в соответствии с результатами, представленными на рисунке 1, выбраны все три главных (линейных) эффекта и два эффекта взаимодействий $X_{1} X_{2}$ и $X_{2} X_{3}$. Уравнение регрессии в этом случае принимает вид

$$
\hat{Y}_{2}=-8,721+0,278 X_{1}+7,810 X_{2}+0,0342 X_{3}-0,130 X_{1} X_{2}-0,0237 X_{2} X_{3}
$$
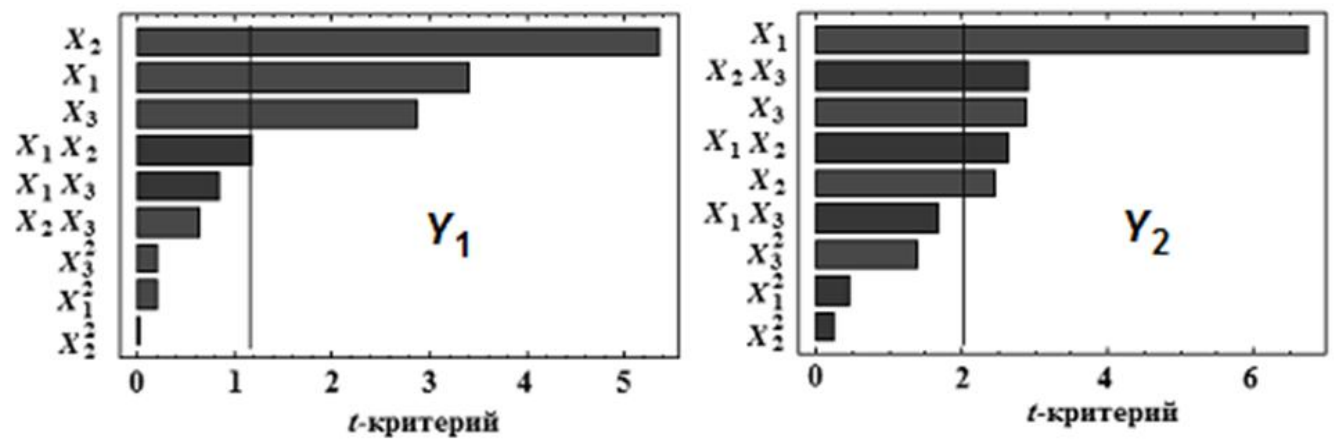

Рис. 1. Диаграммы Парето для выходных параметров $Y_{1}$ «белизна» и $Y_{2}$ «химические потери целлюлозы»
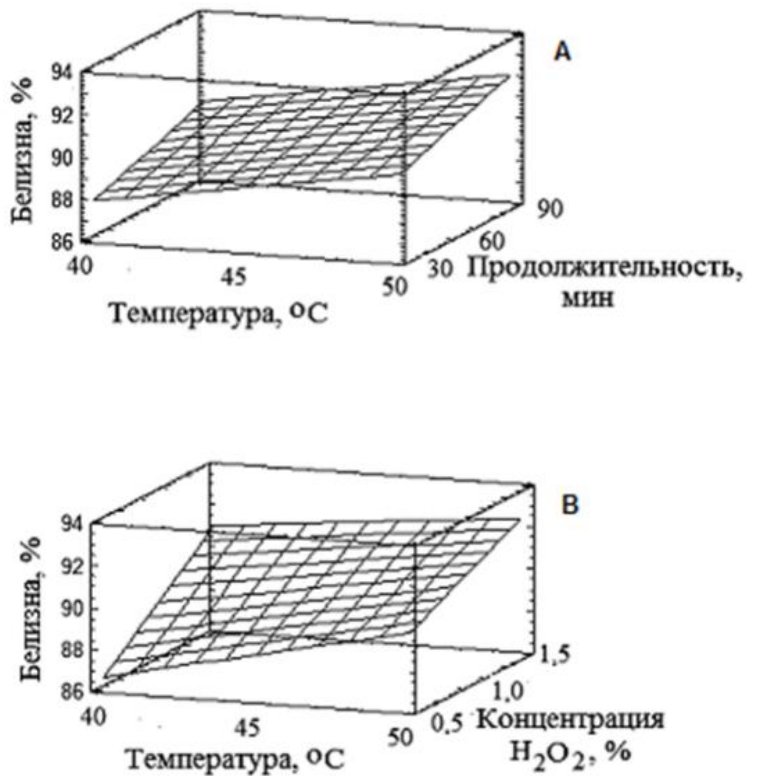

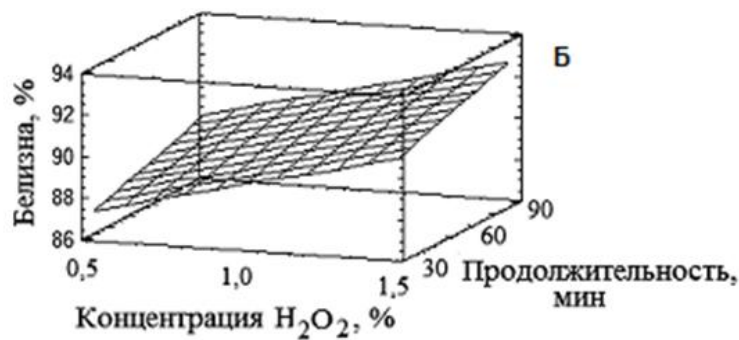

Рис. 2. Зависимость белизны целлюлозы от переменных факторов отбелки:

А - при фиксированной концентрации пероксида водорода $1,0 \%$;

Б - при фиксированной температуре $45^{\circ} \mathrm{C}$;

$\mathrm{B}$ - при фиксированной продолжительности 60 мин 
Таблица 2. Результаты дисперсионного анализа

\begin{tabular}{l|c|c|c|c}
\hline \multirow{2}{*}{$\begin{array}{l}\text { Источники дисперсии и статисти- } \\
\text { ческие характеристики }\end{array}$} & \multicolumn{2}{|c|}{ Белизна, $Y_{1}$} & \multicolumn{2}{|c}{ Химические потери, $Y_{2}$} \\
\cline { 2 - 5 }$X_{1}$ температура & 627,2 & 0,0254 & 273,8 & 0,0384 \\
$X_{2}$ : концентрация $\mathrm{H}_{2} \mathrm{O}_{2}$ & 1566,4 & 0,0161 & 36,4 & 0,1045 \\
$X_{3}$ продолжительность & 441,8 & 0,0303 & 49,9 & 0,0895 \\
$X_{1} X_{2}$ & 76,6 & 0,0724 & 42,2 & 0,0972 \\
$X_{2} X_{3}$ & - & - & 50,4 & 0,0891 \\
Lack-оf-fit & 34,0 & 0,1309 & 6,4 & 0,2940 \\
\hline Коэффициент детерминации $R^{2}, \%$ & \multicolumn{3}{|c|}{88,8} & \\
\hline Критерий Дарбина-Уотсона $(\mathrm{DW})$ & \multicolumn{2}{|c|}{$2,242\left(P_{\mathrm{DW}}=0,234\right)$} & $2,119\left(P_{\mathrm{DW}}=0,343\right)$ \\
\hline
\end{tabular}

Сравнение вычисленных по уравнению (2) прогнозируемых значений выходного параметра $\hat{Y}_{2}$ с экспериментально полученными величинами потерь $Y_{2}$ показало удовлетворительное соответствие между этими величинами. Этот вывод подтверждается результатами дисперсионного анализа, приведенными в таблице 2. Уравнение регрессии (2) адекватно отражает результаты эксперимента, так как величина уровня значимости $P=0,2940$ для дисперсионного $F$-отношения в строке Lack-of-fit значительно превышает критическую величину 0,05 . На хорошие прогностические свойства математической модели указывает высокое значение коэффициента детерминации $R^{2}$. Условие отсутствия корреляции остатков выполняется, поскольку $P_{\mathrm{DW}}=0,343>0,05$.

На рисунке 3 изображены поверхности отклика, иллюстрирующие зависимость величины потерь целлюлозы от переменных факторов процесса отбелки.

Как и следовало ожидать, увеличение каждого из включенных в исследование факторов сопровождается снижением выхода беленой целлюлозы из-за удаления, главным образом, остаточного лигнина, а также небольшой части углеводов. Особенно заметно это проявляется при нижних уровнях температуры и концентрации пероксида водорода, когда химические процессы протекают с меньшей скоростью и «растянуты» во времени. При верхних уровнях значений этих факторов основная часть лигнина удаляется в самом начале процесса отбелки, продолжение процесса мало влияет на величину химических потерь.

Между белизной и химическими потерями целлюлозы существует вполне объяснимая, но слабовыраженная связь, характеризуемая коэффициентом линейной корреляции 0,64. С ужесточением условий отбелки увеличивается положительный эффект - повышение белизны, но одновременно растет и отрицательный эффект - потери целлюлозы вследствие химической деструкции. Следовательно, задача оптимизации процесса является компромиссной и сводится к отысканию в пределах изученного факторного пространства таких условий отбелки, при которых может быть достигнута требуемая белизна при минимальных потерях целлюлозы. В терминах теории оптимизации она формулируется следующим образом: $\hat{Y}_{2} \rightarrow$ $\min$ (целевая функция); $\hat{Y}_{1} \geq 89 \%$ (ограничение другого выходного параметра); $40{ }^{\circ} \mathrm{C} \leq X_{1} \leq 50{ }^{\circ} \mathrm{C} ; 0,5 \% \leq X_{2}$ $\leq 1,5 \% ; 30$ мин $\leq X_{3} \leq 90$ мин (ограничение области поиска в пространстве факторов).
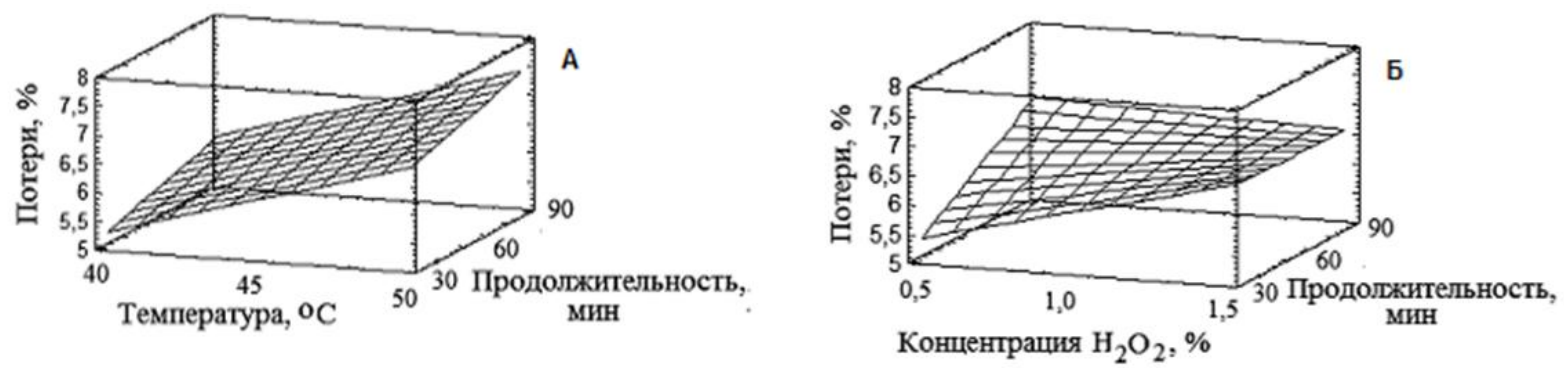


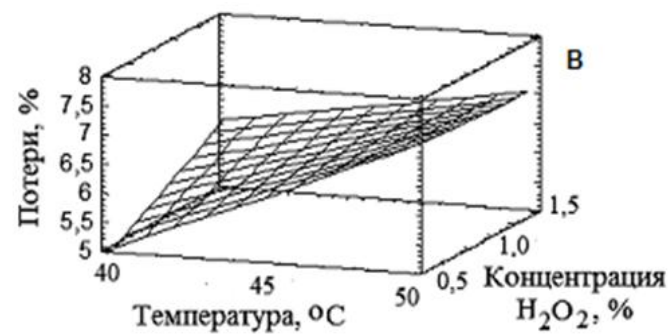

Рис. 3. Зависимость потерь целлюлозы от переменных факторов отбелки: А - при фиксированной концентрации пероксида водорода $1,0 \%$; Б - при фиксированной температуре $45^{\circ} \mathrm{C}$; В - при фиксированной продолжительности 60 мин

Ограничение белизны величиной 89\% продиктовано требованием ГОСТ 28172 «Целлюлоза сульфатная беленая из смеси лиственных пород древесины» к целлюлозе марки ЛС-0 (высший и первый сорта). Целлюлоза из пшеничной соломы по размерам волокон и прочностным свойствам близка к целлюлозе из мягколиственных пород древесины (березы, осины) и может применяться для тех же целей, что и лиственная целлюлоза.

Сформулированная задача решена с использованием средств Еxсеl из программного пакета Мicrosoft Office [4]. Её решение: $X_{1}=40{ }^{\circ} \mathrm{C} ; X_{2}=1 \% ; X_{3}=63$ мин; $\hat{Y}_{1}=89 \% ; \hat{Y}_{2}=5,7 \%$. Вычисленные оптимальные значения близки к условиям и результатам одного из экспериментов реализованного плана (последняя строка в табл. 1).

\section{Заключение}

Небеленая пероксидная целлюлоза из пшеничной соломы по степени белизны соответствует древесной полубеленой сульфитной целлюлозе, превосходит сульфатную полубеленую целлюлозу и может найти применение в производстве некоторых видов бумаги и картона. Отбелка пероксидной соломенной целлюлозы до высокой белизны может быть произведена пероксидом водорода в одну или две ступени по обычной технологии.

\section{Список литературы}

1. Пен Р.З., Коваленко А.А., Грязнов А.С., Каретникова Н.В., Вшивкова И.А. Свойства пероксидной целлюлозы из однолетних растений. 6. Релаксационные переходы в целлюлозе // Химия растительного сырья. 2013. № 4. C. $29-35$.

2. Непенин Н.Н., Непенин Ю.Н. Технология целлюлозы. Т. 3. Очистка, сушка и отбелка целлюлозы. Прочие способы получения целлюлозы. М., 1994. 592 с.

3. Пен Р.3. Планирование эксперимента в Statgraphics Centurion. Красноярск, 2014. 292 c.

4. Курицкий Б.Я. Поиск оптимальных решений средствами Excel 7.0. СПб, 1997. 384 с.

Поступило в редакцию 19 октября 2014 г. 
Pen R.Z., Karetnikova N.V., Vshivkova I.A., Shapiro I.L. PEROXIDE PULPING PROPERTIES OF ANNUAL PLANTS. 7. BLEACHING OF CELLULOSE FROM THE WHEAT STRAW

Siberian State Technological University, pr. Mira 82, Krasnoyarsk 660049 (Russia), e-mail: sibstu@sibstu.ru, robertpen@yandex.ru

Peroxide pulp from wheat straw by cooking had been received by cooking with reactionary mixture $\ll \mathrm{H}_{2} \mathrm{O}_{2}-\mathrm{H}_{2} \mathrm{O}-\mathrm{AcOH}-$ AcOOH-catalyst». The bleaching was produced by hydrogen peroxide at $\mathrm{pH} 10,5$ and at concentration of fibrous suspension $10 \%$ in one stage in accordance to accepted technology for this process. Dependence of the whiteness and chemical loss from the hydrogen peroxide concentration (range $0,5-1,5 \%)$, temperature $\left(40-50{ }^{\circ} \mathrm{C}\right)$ and bleaching duration $(30-90 \mathrm{~min})$ had approximated by regression equation of second order. It was found the easy bleaching of the peroxide straw cellulose. Optimal bleaching conditions was found by nonlinear programming method: temperature $40{ }^{\circ} \mathrm{C}$; concentration $\mathrm{H}_{2} \mathrm{O}_{2} 1 \%$; duration $63 \mathrm{~min}$. Bleaching results to optimal condition: cellulose whiteness $89 \%$ (correspond to State Standard for hard wood sulfate cellulose), chemical loss 5,7\%.

Keywords: peroxide pulp, pulp from straw, peroxide cooking, pulp bleaching.

\section{References}

1. Pen R.Z., Kovalenko A.A., Grjaznov A.S., Karetnikova N.V., Vshivkova I.A. Himija rastitel'nogo syr'ja, 2013, no. 4, pp. 29-35. (in Russ.).

2. Nepenin N.N., Nepenin Yu.N. Tekhnologiia tselliulozy. [Cellulose technology]. Moscow, 1994, vol. 3, 596 p. (in Russ.).

3. Pen R.Z. Planirovanie eksperimenta v Statgraphics Centurion. [Design of experiment in Statgraphics Centurion]. Krasnoyarsk, 2014, 292 p. (in Russ.).

4. Kuritskii B.Ya. Poisk optimal'nikh reshenii sredstvami Excel 7.0. [Search of the optimal solution with Excel 7.0 way]. St. Petersburg, 1997, 384 p. (in Russ.).

Received October 19, 2014

Revised May 15, 2015

\footnotetext{
* Corresponding author.
} 